\title{
Evaluation of the C-domain of heparanase during AGE-induced macrophage inflammatory response
}

\author{
QIAOJING QIN $^{1}$, GUANG XU ${ }^{1}$, WEIWEI QI ${ }^{1}$, MEI GUO $^{1}$, ZHAOXIA WANG $^{2}$, WANGJIE XU ${ }^{2}$, \\ ZHONGDONG QIAO ${ }^{2}$, YONG GU ${ }^{1}$ and JIANYING NIU ${ }^{1}$ \\ ${ }^{1}$ Department of Nephrology, The Fifth People's Hospital of Shanghai, Fudan University; ${ }^{2}$ School of Life Science \\ and Biotechnology, Shanghai Jiao Tong University, Shanghai 200240, P.R. China
}

Received July 15, 2016; Accepted April 18, 2017

DOI: $10.3892 / \mathrm{etm} .2017 .4609$

\begin{abstract}
Diabetic vasculopathy is intensified by macrophage inflammation caused by advanced glycation end products (AGEs). Heparanase (HPA) is a unique endoglycosidase, which cleaves heparan sulfate proteoglycans (HSPGs) including syndecan-1 (Syn-1) to further stimulate macrophage cell migration and inflammation. The present study was planned to evaluated the role of C-domain (if any) of HPA in AGE inflammatory response in macrophages. Cell viability was assessed using MTT assay, migration assay, ELISA for tumor necrosis factor- $\alpha$ (TNF- $\alpha)$, interleukin-1 $\beta$ (IL-1 $\beta$ ) levels, mRNA expression by RT-PCR and heparan degrading enzyme assay for HPA activity. In the present study, we found that pretreatment with anti-HPA antibody, which recognizes the C-domain of HPA inhibited macrophage migration, secretion of IL-1 $\beta$ and TNF- $\alpha$ as well as decreased HPA enzymatic activity and increased Syn-1 protein expression in AGE-induced macrophages. Compared with anti-HPA antibody pretreatment, co-pretreatment with anti-HPA plus Syn-1 antibodies promoted macrophage migration, and secretion of IL-1 $\beta$ and TNF- $\alpha$ significantly in AGE-induced macrophages. In addition, pretreatment with anti-HPA or anti-HPA plus Syn-1 antibodies did not markedly change the mRNA levels of IL-1 $\beta$ and TNF- $\alpha$ concentration AGE-treated macrophages. The results showed that $\mathrm{C}$-domain of HPA mediates AGE-induced macrophage migration and inflammatory cytokine release via Syn-1 protein expression. Furthermore, C-domain of HPA may have a key role in diabetic vascular complication-associated inflammatory response.
\end{abstract}

Correspondence to: Dr Jianying Niu, Department of Nephrology, The Fifth People's Hospital of Shanghai, Fudan University, 128 Ruili Road, Shanghai 200240, P.R. China

E-mail: njyphd2008@163.com

Key words: advanced glycation end products, macrophage, inflammatory response, diabetes, heparanase, syndecan-1

\section{Introduction}

Advanced glycation end products (AGEs) (formed by non-enzymatic modification of proteins, lipids and nucleic acids by glucose), accumulated by sustained hyperglycemia, are responsible for diabetic vascular complications (1). AGEs evoke inflammatory response-associated macrophage migration, filtration and inflammatory cytokine release $(2,3)$. Although AGEs and inflammation are critical for diabetic vascular complications, knowledge regarding the relationship between AGEs and inflammatory response involving macrophage migration, filtration and inflammatory cytokine release is still unclear.

Heparanase (HPA), a unique and specific functional endo- $\beta$-D-glucuronidase, cleaves heparan sulfate (HS) chains for remodeling of extracellular matrix and regulation of the release of many HS-linked molecules such as growth factors, and cytokines $(4,5)$. Previous findings showed that deletion of the C-domain of HPA generated enzymatically inactive HPA (6). Thus, the C-terminal domain may be essential for HPA enzymatic activity. On the other hand, syndecans are a family of HS-decorated cell-surface proteoglycans degraded by HPA (7). Syndecan-1 (Syn-1), a member of the syndecan family, which comprises HP proteoglycans (HSPGs), displayed the capacity to modulate cell migration and inflammatory responses by binding chemokines and cytokines $(8,9)$. A study has shown that HPA has the ability to regulate Syn-1 expression (10).

Based on the above studies, we speculated that HPA may mediate AGEs-induced inflammatory response via Syn-1 protein expression. Therefore, we examined the relation between C-domain of HPA and Syn-1 in AGE-induced macrophage migration and inflammation. Inflammatory response mediators including, tumor necrosis factor- $\alpha$ (TNF- $\alpha$ ) and interleukin-1 $\beta$ (IL-1 $\beta$ ), were studied to evaluate the role of $\mathrm{C}$-domain of HPA between AGEs and inflammatory response in macrophages.

\section{Materials and methods}

Cell culture. Macrophage cells (the Cell Bank of the Shanghai Institutes for Biological Sciences, Chinese Academy of Sciences, Shanghai, China) were cultured in RPMI-1640 
medium containing $10 \%$ heat-inactivated fetal bovine serum (FBS), $100 \mathrm{U} / \mathrm{ml}$ penicillin and $100 \mu \mathrm{g} / \mathrm{ml}$ streptomycin. Cells were cultured at $37^{\circ} \mathrm{C}$ in a humidified incubator, in which the concentration of $\mathrm{CO}_{2}$ was $5 \%$, and were used in the exponential growth phase.

Cell viability analysis by 3-(4, 5-dimethylthiazol-2-yl)-2,5-diphenyltetrazolium bromide (MTT) assay. Macrophages were plated at $5 \times 10^{4}$ cells $/ \mathrm{ml}$ and incubated with or without AGEs (Shanghai Yixin Biotechnology Co., Ltd., Shanghai, China), and antibody against C-domain of HPA (Wuhan Boster Bio-Engineering Co., Ltd., Wuhan, China) or anti-HPA plus Syn-1 antibody (R\&D Systems, Inc., Minneapolis, MN, USA) was applied for various periods of time (4-24 h). After incubation, MTT solution was added to each well for $4 \mathrm{~h}$. DMSO was added to dissolve the formazan crystals formed. Finally, the plates were read by a microplate reader after the blue salt in each well was dissolved.

Cell treatments. The cells were treated with AGEs $(0,25$, 50 and $100 \mathrm{mg} / \mathrm{l}$ ), and anti-HPA or anti-HPA plus Syn-1 antibody for $24 \mathrm{~h}$, respectively, and were analyzed by migration assay. RT-PCR and enzyme-linked immunosorbent assay (ELISA) were performed to evaluate the role of C-domain of HPA and Syn-1 in AGE-induced macrophage migration and release of inflammatory cytokine IL- $1 \beta$ or TNF- $\alpha$. Subsequently, the cells were treated with $100 \mathrm{mg} / \mathrm{l} \mathrm{AGEs}$, and anti-HPA antibody for $24 \mathrm{~h}$. This was followed by analyses with the help of heparan degrading enzyme assay in order to examine the effects of C-domain of HPA on HPA enzyme activity in AGE-induced macrophages. Finally, the cells were treated with $100 \mathrm{mg} / \mathrm{l}$ AGEs, and anti-HPA antibody for $24 \mathrm{~h}$, and harvested for western blot analysis to assess of the role of the C-domain of HPA in AGE-induced Syn-1 expression.

Migration assay. Macrophages were seeded onto the upper chamber of 6-well Transwell plates (Becton Dickinson, Franklin Lakes, NJ,USA) with $8 \mu$ m pores. Medium containing $2 \%$ FBS was used in the lower chamber. After $6 \mathrm{~h}$, the cells were removed from the upper surface of the filter with cotton swabs. Macrophages migrated to the Transwell were fixed with $4 \%$ paraformaldehyde. Migrated macrophages were then stained with hematoxylin and subsequently counted (6 random fields/slide).

ELISA for TNF- $\alpha$, and IL-1 $\beta$. The levels of TNF- $\alpha$ and IL-1 $\beta$ in culture supernatants were determined using ELISA kits (Wuhan Boster Bio-Engineering Co., Ltd.) according to the manufacturer's instructions. The levels of TNF- $\alpha$ and IL-1 $\beta$ were quantified using a standard curve established by a serial dilution of standard concentration.

Detection of mRNAs by RT-qPCR. Total RNA from macrophages was isolated with TRIzol reagent. Isolated RNA was reversed transcribed into complementary DNA by RevertAid First Strand cDNA Synthesis kit (Fermentas, Vilnius, Lithuania). RT-qPCR was used for First Strand DNA and to further amplify specific cDNA fragments over 35 cycles using RNA PCR kit (Takara Biotechnology Co., Ltd., Dalian,
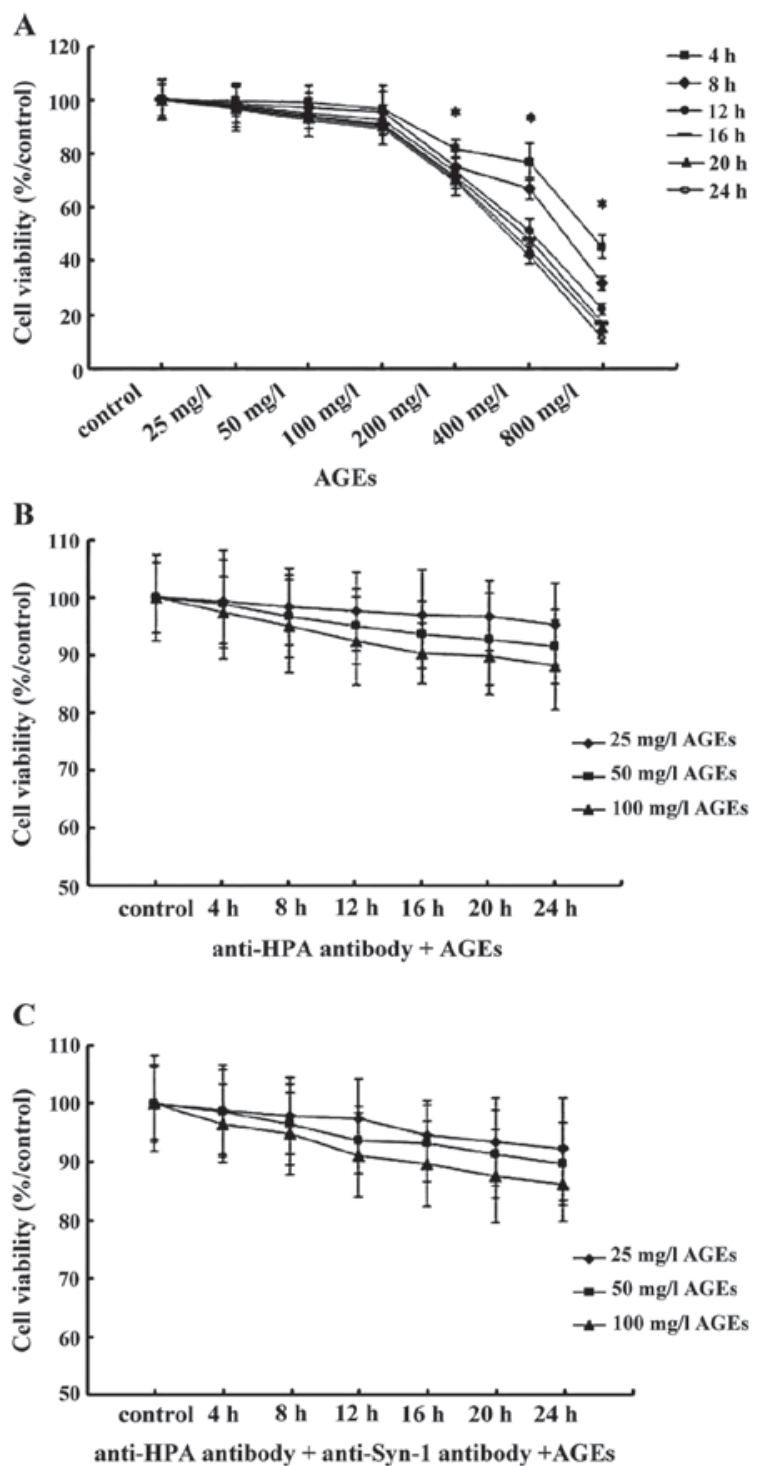

Figure 1. The viability of macrophages treated with AGEs, anti-HPA and Syn-1 antibody. The viability of macrophages was measured using MTT. (A) Macrophages were treated with AGEs (0, 25, 50, 100, 200, 400 and $800 \mathrm{mg} / \mathrm{l}$ ) for 4, 8, 12, 16, 20 and $24 \mathrm{~h}$. (B) Macrophages were pretreated with anti-HPA before culture with 25, 50 and $100 \mathrm{mg} / 1$ AGEs for 4, 8, 12, 16, 20 and $24 \mathrm{~h}$. (C) Macrophages were pretreated with antiHPA plus anti-Syn-1 antibody before culture with 25, 50 and $100 \mathrm{mg} / 1$ AGEs for 4, 8, 12, 16, 20 and $24 \mathrm{~h}$. The results are the mean of 6 culture wells (mean $\pm \mathrm{SEM}$ ). ${ }^{*} \mathrm{P}<0.05$, as compared to the control group. All of the experiments were performed independently in triplicate. AGEs, advanced glycation end products; HPA, heparanase; Syn-1, syndecan-1.

China). The amount of TNF- $\alpha$ and IL-1 $\beta$ was determined and normalized by the amount of GAPDH cDNA.

Western blot analysis. Total cell lysates were obtained by dissociation solution containing protease inhibitors and PMSF. Purified proteins were subjected to SDS-PAGE, transferred onto a nitrocellulose membrane and probed with anti-Syn-1 antibody (polyclonal goat $\operatorname{IgG}, 1: 1,000$ dilution and cat. no. AF3190 ). A second peroxidase-conjugated Ab (polyclonal rabbit IgG, 1:10,000 dilution and cat. no. BA1060) was used and the activity was detected using enhanced chemiluminesence detection system. Anti-GAPDH antibody (polyclonal 


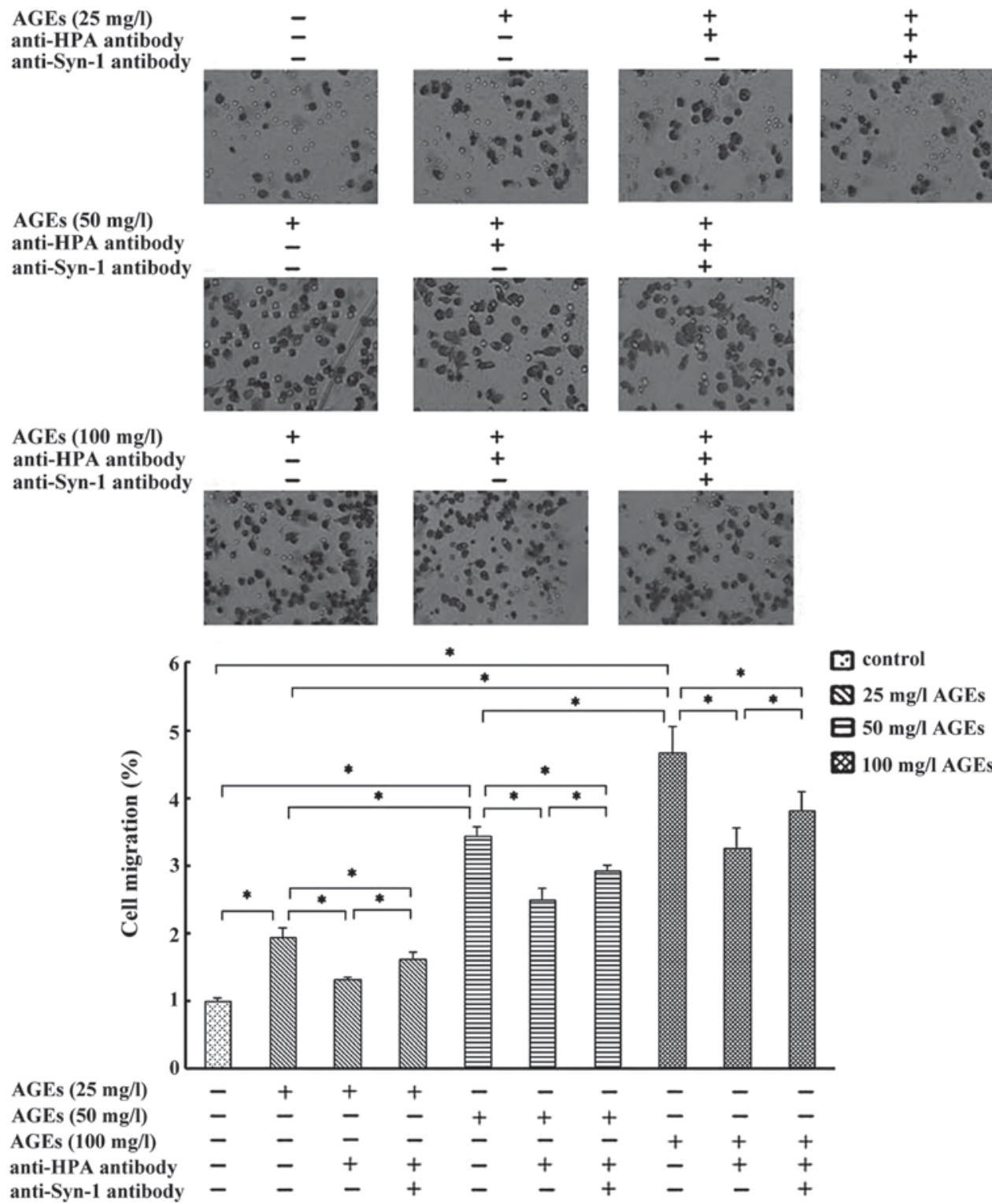

Figure 2. C-domain of HPA mediates AGE-induced macrophage migration via Syn-1. Cells were cultured with 25,50 and $100 \mathrm{mg} / 1$ AGEs for $24 \mathrm{~h}$ with or without pre-treatment with anti-HPA or anti-HPA plus anti-Syn-1 antibody, respectively. The migration was measured by Transwell assays. Results were normalized to the number of macrophages that migrated in the control group. The results are the mean of 6 culture wells (mean \pm SEM). "P<0.05. All of the experiments were performed independently in triplicate. HPA, heparanase; AGEs, advanced glycation end products; Syn-1, syndecan-1.

goat $\operatorname{IgG}, 1: 1,000$ dilution and cat. no. sc-48167) was used as a loading control.

Heparan degrading enzyme assay for HPA activity. The medium was collected from each culture plate. HPA activity was assessed using a heparan degrading enzyme assay kit (Otsu, Shiga, Japan). A standard curve was established using the standards; plot enzyme activity on the $\mathrm{x}$-axis and the corresponding absorbance on the $y$-axis. The enzymatic activity was then calculated corresponding to each sample's measured absorbance.

Statistical analysis. Data were expressed as mean \pm SEM. Statistical analysis was performed by SPSS statistical software (SPSS, Inc., Chicago, IL, USA) using one-way analysis of variance (ANOVA). $\mathrm{P}<0.05$ was considered to indicate a statistically significant difference.

\section{Results}

Cell viability. Cell viability was decreased significantly following exposure to AGE concentrations of $200 \mu \mathrm{M}$ and higher for $24 \mathrm{~h}$. No significant difference of the cell viability was observed in 25-100 mg/l AGE-treated macrophage following 4-24 h treatments (Fig. 1A). Therefore, we chose the concentration of AGEs $\leq 100 \mathrm{mg} / \mathrm{l}$, as these concentrations did not change the cell viability significantly in the 4-24 h incubation.

Subsequently, macrophages were pre-treated with $10 \mu \mathrm{g} / \mathrm{ml}$ antibody that recognized the C-domain of HPA, and $10 \mu \mathrm{g} / \mathrm{ml}$ anti-Syn-1 antibody, before culture with 25-100 mg/l AGEs for 4 to 24 h except control group. No significant change in macrophage viability was observed in the studied concentrations for $24 \mathrm{~h}$ (Fig. 1B and C). Therefore, 25-100 mg/l AGE incubation with macrophages for $24 \mathrm{~h}$ after pretreatment with $10 \mu \mathrm{g} / \mathrm{ml}$ 
A
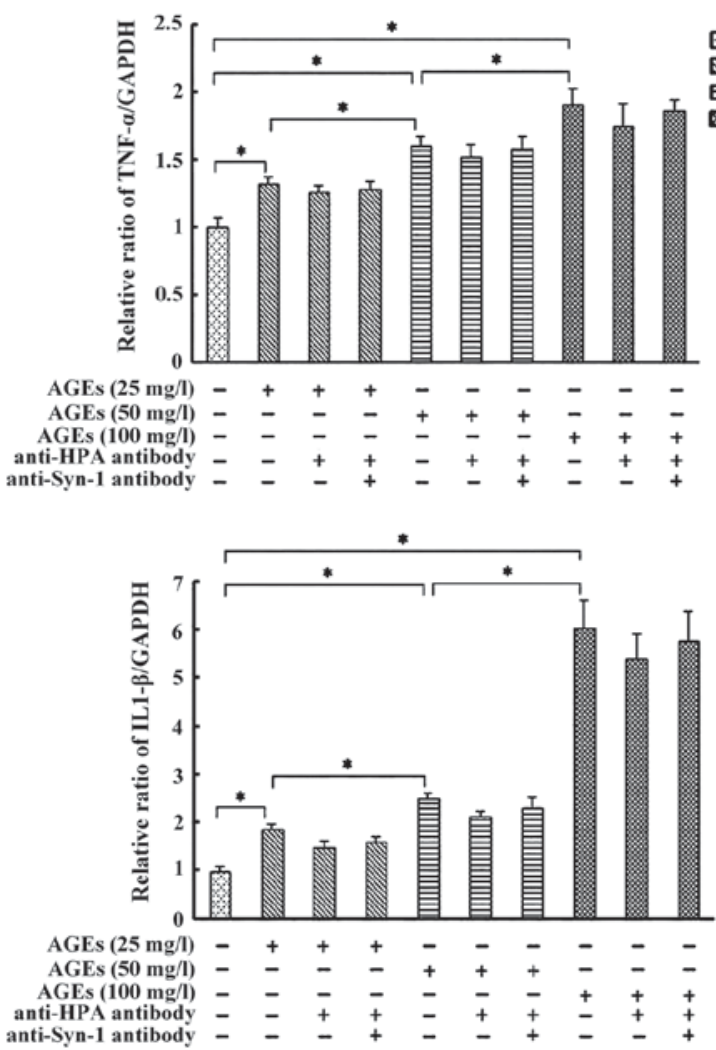

B

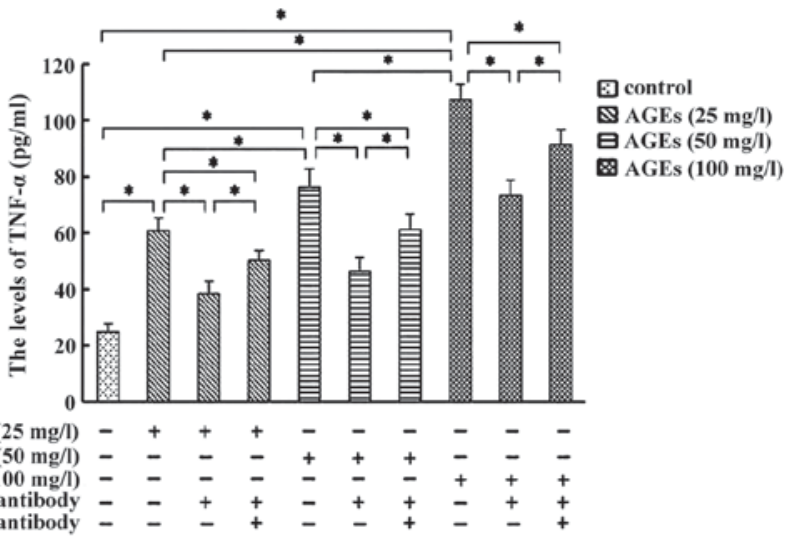

AGEs $(25 \mathrm{mg} / \mathrm{l})$

日AGEs $(50 \mathrm{mg} / \mathrm{l})$

Q AGEs (100 mg/l)

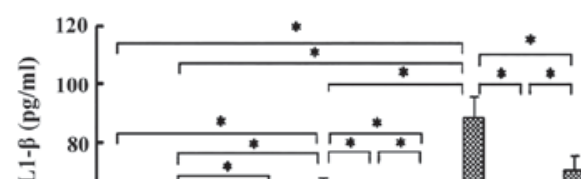

Q control
Q AGEs $(25 \mathrm{mg} / \mathrm{l})$
日 AGEs $(50 \mathrm{mg} / \mathrm{l})$

日 AGEs $(50 \mathrm{mg} / \mathrm{l})$

GEs $(100 \mathrm{mg} / \mathrm{l})$
要

吾

20

${ }_{0}{ }^{40}$

(l)

-
$=$
$=$

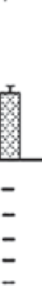

Figure 3. C-domain of HPA mediated release of inflammatory factor TNF- $\alpha$ and IL-1 $\beta$ in AGE-induced macrophages via Syn-1. Cells cultured with 25 , 50 and $100 \mathrm{mg} / 1$ AGEs for $24 \mathrm{~h}$ with or without pre-treatment with anti-HPA antibody recognized C-domain of HPA or anti-HPA plus Syn-1 antibody. (A) The mRNA levels of TNF- $\alpha$ and IL-1 $\beta$ were assessed with RT-qPCR. (B) The secretion of TNF- $\alpha$ and IL- $1 \beta$ in supernatant was measured by ELISA. The results are the mean of 6 culture wells (mean \pm SEM). ${ }^{*} \mathrm{P}<0.05$. All of the experiments were performed independently in triplicate. HPA, heparanase; TNF- $\alpha$, tumor necrosis factor- $\alpha$; IL-1 $\beta$, interleukin-1 $\beta$; AGEs, advanced glycation end products; Syn-1, syndecan-1; ELISA, enzyme-linked immunosorbent assay.

anti-HPA antibody, and $10 \mu \mathrm{g} / \mathrm{ml}$ anti-Syn-1 antibody was selected for further experiments.

C-domain of HPA mediates AGE-induced macrophage migration via Syn-1. AGEs (25-100 mg/l) induced a non-linear concentration-dependent significant increase for $24 \mathrm{~h}$ in macrophage migration. Pretreatment with the antibody recognized the C-domain of HPA, thereby decreasing the AGE-induced macrophages migration significantly (Fig. 2). These results indicated that C-domain of HPA mediates AGEs-induced macrophage migration. Compared with anti-HPA antibody pretreatment, the co-pretreatment with anti-HPA antibody and anti-Syn-1 antibody markedly promoted cell migration in 25-100 mg/l AGE-induced macrophage but not to the levels close to the control (Fig. 2). These results suggested that AGE-induced macrophage migration may be mediated by C-domain of HPA via Syn-1.

$C$-domain of HPA mediates the release of TNF- $\alpha$ and $I L-1 \beta$ via Syn-1 in AGE-induced macrophages. We observed that treatment of Ana-1 macrophages with AGEs promoted a non-linear concentration-dependent increase in the secretion of IL-1 $\beta$ and TNF- $\alpha$ significantly. Moreover, pretreatment with anti-HPA antibody significantly inhibited the secretion of IL-1 $\beta$ and TNF- $\alpha$, whereas the inhibition was markedly attenuated by co-pretreatment with anti-HPA and Syn-1 antibody, while pretreatment of anti-HPA or anti-HPA plus Syn-1 antibody did not significantly affect the mRNA levels of IL-1 $\beta$ and TNF- $\alpha$ in the identical concentration of AGE-induced macrophages, respectively (Fig. 3A and B). These results suggested that $\mathrm{C}$-domain of HPA mediated the release of inflammation cytokine IL-1 $\beta$ and TNF- $\alpha$ in AGE-induced macrophage via Syn-1 independently of IL-1 $\beta$ and TNF- $\alpha$ mRNA expression.

AGE stimulation increased HPA enzyme activity and decreased Syn-1 protein C-domain dependence-domain. Data from earlier studies confirmed that HPA enzyme activity and Syn-1 were crucial for inflammation. HPA enzymatic activity was observed to cause degradation of Syn-1 in order to release Syn-1 binding cytokines. To address the effect of C-domain of HPA on HPA enzyme activity and Syn-1 protein, we selected the maximum concentration of AGEs $(100 \mathrm{mg} / \mathrm{l})$ that induced the maximum cell migration and secretion of IL-1 $\beta$ and TNF- $\alpha$. We observed that AGEs promoted HPA activity and inhibited the protein expression of Syn-1 significantly in macrophages. Moreover, pretreatment with the antibody that recognized C-domain of HPA significantly inhibited HPA activity and elevated the protein expression of Syn-1 in AGE-induced macrophages (Fig. 4). These results indicated 
A
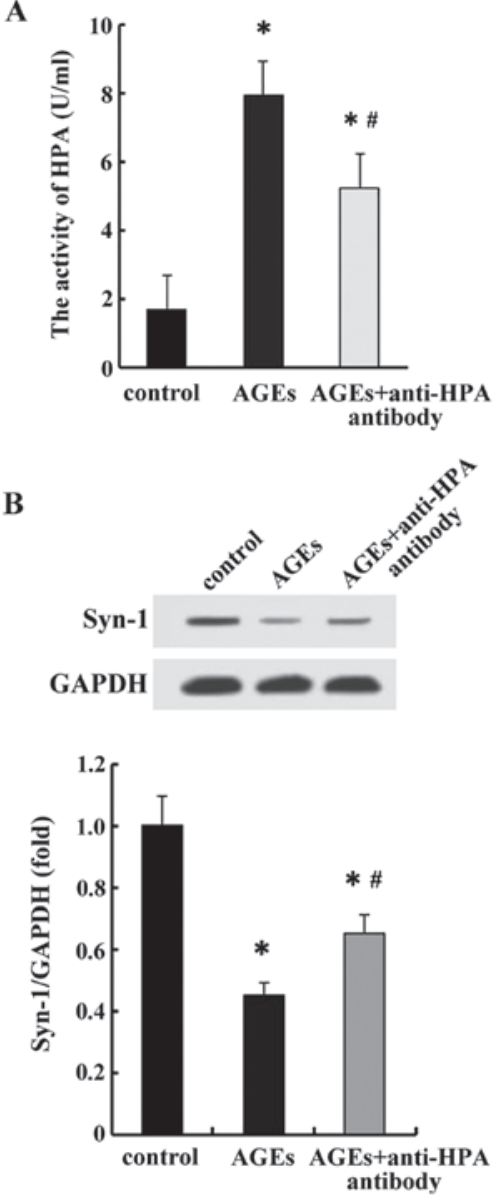

Figure 4. Effects of C-domain of HPA on the HPA activity and Syn-1 protein in AGE-induced macrophages. Cells were cultured with $100 \mathrm{mg} / \mathrm{l}$ AGEs for $24 \mathrm{~h}$ with or without pre-treatment with anti-HPA antibody recognized C-terminal of HPA. (A) The enzyme activity of HPA was evaluated by heparan degrading enzyme assay. (B) The Syn-1 protein expression was performed by western blot analysis. The results are the mean of 6 culture wells (mean \pm SEM). All the experiments were performed independently in triplicate. $\mathrm{P}<0.05$ significantly different from control $(0 \mathrm{mg} / \mathrm{l})$ and AGEs at $100 \mathrm{mg} / \mathrm{l} ;{ }^{\prime} \mathrm{P}<0.05$ significantly different from AGEs at $100 \mathrm{mg} / 1$. HPA, heparanase; AGEs, advanced glycation end products; Syn-1, syndecan-1.

that AGEs promoted HPA enzyme activity and inhibited Syn-1 protein expression that in turn was observed to be mediated by C-domain of HPA. Thus, C-domain of HPA could regulate inflammatory response via HPA enzyme activity associated with Syn-1 protein.

\section{Discussion}

AGEs and inflammation induced by macrophage have emerged as the important mechanistic components responsible for diabetic vascular complications (1). Previous studies have shown that AGEs evoke inflammation (11). However, the key molecule responsible for these complications remains unclear. The present study revealed that C-domain of HPA is crucial for AGE-induced macrophage inflammatory response and migration via Syn-1 expression.

Our initial experiment was aimed to select the appropriate AGE concentration and time for further experimentation by MTT assay. Exposure of macrophage cultures to increasing concentrations of AGEs for 4, 8, 12, 16, 20 and $24 \mathrm{~h}$ resulted in dose- and time-dependent inhibition, but nonlinear dose and time response to cell viability. Marked inhibition was observed following treatments with AGE concentrations of $200 \mathrm{mg} / \mathrm{l}$ or higher for 4, 8, 12, 16, 20 and $24 \mathrm{~h}$. The results did not reveal any differences in the range of $25-100 \mathrm{mg} / \mathrm{l}$ for $24-\mathrm{h}$ incubation period. Thus, we chose the concentration of AGEs of not more than $100 \mathrm{mg} / \mathrm{l}$ for $24 \mathrm{~h}$ culture for further experimentation in the present study. Subsequently, pretreatment with $10 \mu \mathrm{g} /$ $\mathrm{ml}$ anti-HPA antibody or $10 \mu \mathrm{g} / \mathrm{ml}$ anti-HPA plus $10 \mu \mathrm{g} / \mathrm{ml}$ anti-Syn-1 antibody revealed a decreased tendency but not marked difference in the viability of macrophages incubated at 25,50 and $100 \mathrm{mg} / 1$ AGEs, respectively. We utilized preincubation of $10 \mu \mathrm{g} / \mathrm{ml}$ anti-HPA antibody, and $10 \mu \mathrm{g} / \mathrm{ml}$ anti-Syn- 1 plus $10 \mu \mathrm{g} / \mathrm{ml}$ anti-HPA antibody along with tested AGE concentration range for $24 \mathrm{~h}$, in further experiments on macrophages.

HPA is the unique and specific functional endoglycosidase. Extracellular HPA exerted its enzymatic activity to cleave HS chains from HSPGs. It resulted in remodeling of the extracellular matrix to enhance cell migration and release many HS-linked molecules such as cytokines involved in inflammation (12). Recent data demonstrated that the $\mathrm{COOH}$-terminal domain (C-domain) of HPA was critical for HPA enzymatic activity (6).

We studied the role of C-domain of HPA in AGE-induced macrophage migration and release of inflammatory cytokines. These results confirmed that the C-domain of HPA mediated the AGE-induced macrophage inflammatory response. Recent data from other studies also supported the fact that Syn-1, a member of HS proteoglycan, regulates various inflammatory processes involving cell migration and binding cytokines $(8,13,14)$. In the lung, Syn-1 attenuated allergic lung inflammation by suppressing Th2 cell recruitment (15). In acute myocardial infarction and remodeling, Syn-1 protected against exaggerated inflammation and adverse infarct healing, thereby reducing cardiac dilatation and dysfunction (16). Furthermore, in endothelial cells, loss of Syn-1 resulted in a pro-inflammatory phenotype (17). In the present study, the treatment of similar AGE-induced macrophages, with anti-HPA or anti-HPA plus anti-Syn-1 antibody, did not significantly affect the mRNA expression of TNF- $\alpha$ and IL-1 $1 \beta$. This result revealed that C-domain of HPA and Syn-1 may regulate the release of TNF- $\alpha$ and IL- $1 \beta$ through post-transcription

Moreover, in the present study, AGEs led to a significant increase in extracellular HPA activity and this response is diminished by the pretreatment of antibody recognized $\mathrm{C}$-domain of HPA. The above observation clearly defined the role of C-domain in AGE-induced HPA enzymatic activity in macrophage. On the basis of HPA enzyme activity associated with C-domain of HPA and Syn-1 protein expression (HPA degrades HSPG include Syn-1), our results further supported that AGEs could decrease Syn-1 protein expression via AGE-induced HPA activity associated with C-domain of HPA.

In conclusion, the present findings show that $\mathrm{C}$-domain of HPA mediates AGE-induced inflammation-associated macrophages involving HPA enzymatic activity and Syn-1 protein expression. The study provided novel insights into the role of C-domain of HPA in AGE-induced macrophage inflammatory response associated with vascular complication of diabetes. 


\section{Acknowledgements}

This study was supported by a grant from the Natural Science Foundation of Shanghai Municipality (13ZR1432600), Key Disease Project of Integrated Traditional and Western Medicine of Shanghai Municipality (zxbz2012-19), Key Basic Research Project of the Science and Technology Commission of Shanghai Municipality (2010-10JC1413000), and the National Natural Science Foundation of China (2009-30871175).

\section{References}

1. Stinghen AE, Massy ZA, Vlassara H, Striker GE and Boullier A: Uremic toxicity of advanced glycation end products in CKD. J Am Soc Nephrol 27: 354-370, 2016.

2. Hodgson K, Morris J, Bridson T, Govan B, Rush C and Ketheesan N: Immunological mechanisms contributing to the double burden of diabetes and intracellular bacterial infections. Immunology 144: 171-185, 2015.

3. Wen Y, Gu J, Li SL, Reddy MA, Natarajan R and Nadler JL: Elevated glucose and diabetes promote interleukin-12 cytokine gene expression in mouse macrophages. Endocrinology 147: 2518-2525, 2006.

4. Masola V, Zaza G, Onisto M and Gambaro G: Heparanase: another renal player controlled by vitamin D. J Pathol 238: 7-9, 2016.

5. Goldberg R, Rubinstein AM, Gil N, Hermano E, Li JP, van der Vlag J, Atzmon R, Meirovitz A and Elkin M: Role of heparanase-driven inflammatory cascade in pathogenesis of diabetic nephropathy. Diabetes 63: 4302-4313, 2014.

6. Fux L, Feibish N, Cohen-Kaplan V, Gingis-Velitski S, Feld S, Geffen C, Vlodavsky I and Ilan N: Structure-function approach identifies a $\mathrm{COOH}$-terminal domain that mediates heparanase signaling. Cancer Res 69: 1758-1767, 2009.

7. Ridgway LD, Wetzel MD and Marchetti D: Modulation of GEF-H1 induced signaling by heparanase in brain metastatic melanoma cells. J Cell Biochem 111: 1299-1309, 2010.
8. Wang C, Tseng T, Jhang Y, Tseng J, Hsieh C, Wu WG and Lee S: Loss of cell invasiveness through PKC-mediated syndecan-1 downregulation in melanoma cells under anchorage independency. Exp Dermatol 23: 843-849, 2014.

9. Hassan H, Greve B, Pavao MS, Kiesel L, Ibrahim SA and Götte M: Syndecan-1 modulates $\beta$-integrin-dependent and interleukin-6-dependent functions in breast cancer cell adhesion, migration, and resistance to irradiation. FEBS J 280: 2216-2227, 2013

10. Orecchia P, Conte R, Balza E, Petretto A, Mauri P, Mingari MC and Carnemolla B: A novel human anti-syndecan-1 antibody inhibits vascular maturation and tumour growth in melanoma. Eur J Cancer 49: 2022-2033, 2013.

11. Moran C, Münch G, Forbes JM, Beare R, Blizzard L, Venn AJ, Phan TG, Chen J and Srikanth V: Type 2 diabetes, skin autofluorescence, and brain atrophy. Diabetes 64: 279-283, 2015.

12. Goodall KJ, Poon IK, Phipps S and Hulett MD: Soluble heparan sulfate fragments generated by heparanase trigger the release of pro-inflammatory cytokines through TLR-4. PLoS One 9: e109596, 2014.

13. Wang Z, Li R, Tan J, Peng L, Wang P, Liu J, Xiong H, Jiang B and Chen Y: Syndecan-1 acts in synergy with tight junction through Stat3 signaling to maintain intestinal mucosal barrier and prevent bacterial translocation. Inflamm Bowel Dis 21: 1894-1907, 2015.

14. Kharabi Masouleh B, Ten Dam GB, Wild MK, Seelige R, van der Vlag J, Rops AL, Echtermeyer FG, Vestweber D, van Kuppevelt TH, Kiesel L, et al: Role of the heparan sulfate proteoglycan syndecan-1 (CD138) in delayed-type hypersensitivity. J Immunol 182: 4985-4993, 2009.

15. Xu J, Park PW, Kheradmand F and Corry DB: Endogenous attenuation of allergic lung inflammation by syndecan-1. J Immunol 174: 5758-5765, 2005.

16. Lei J, Xue S, Wu W, Zhou S, Zhang Y, Yuan G and Wang J: Sdc1 overexpression inhibits the $\mathrm{p} 38$ MAPK pathway and lessens fibrotic ventricular remodeling in MI rats. Inflammation 36: 603-615, 2013.

17. Voyvodic PL, Min D, Liu R, Williams E, Chitalia V, Dunn AK and Baker AB: Loss of syndecan-1 induces a pro-inflammatory phenotype in endothelial cells with a dysregulated response to atheroprotective flow. J Biol Chem 289: 9547-9559, 2014. 